ORIGINAL ARTICLE

\title{
The intubating laryngeal mask: is there a role for paramedics?
}

\section{Robert Menzies, Hamid Manji}

See end of article for

authors' affiliations

......................

Correspondence to:

Dr R W Menzies,

Northampton General

Hospital, Cliftonville,

Northampton NN1 5BD,

UK;

drrmenzies@hotmail.com

Accepted 8 October 2006
Objective: To compare the ability of UK paramedics to intubate a simulated difficult airway using a Mackintosh laryngoscope versus an intubating laryngeal mask airway (ILMA).

Method/Design: A randomised controlled trial.

Results: $100 \%$ of the paramedics were able to intubate a simulated difficult airway using the ILMA versus $0 \%$ of those using the Mackintosh laryngoscope.

Conclusions: This study has demonstrated the ability of paramedics to use the ILMA when faced with a difficult intubation. However, further evaluation of this potential role for the ILMA is required.
$\mathrm{T}$ he intubating laryngeal mask airway (ILMA) has a proven role in unexpected difficult intubation. ${ }^{1-4}$ It has also been demonstrated to be effective in those with limited airway experience. $^{5-7}$

This is a prospective randomised controlled trial of the ability of UK paramedics to use the ILMA in a simulated difficult intubation in a hospital environment.

\section{METHOD}

Local ethical committee approval was gained before commencement of the study.

Paramedics involved in this trial were based at the Three Shires Ambulance Service and had no previous exposure to the ILMA.

All candidates received a tutorial on the ILMA, consisting of a short lecture and instructions on its insertion. Demonstration of ILMA removal after intubation (leaving the endotracheal tube in situ) was not performed.

The Mannequin used for both scenarios was the ALS 4000 (Laerdal), which was adapted by placing padding underneath the tongue to simulate a difficult airway. The best view at laryngoscopy obtained by the authors was grade 3 (epiglottis visible, no vocal cords visible). ${ }^{8}$ Bag-mask ventilation was not assessed as the Mannequin was unable to simulate both a failed bag-mask ventilation and a failed intubation concurrently.

Candidates were informed that this was a simulated difficult intubation scenario.

Each candidate was randomly allocated to perform scenarios $\mathrm{A}$ and $\mathrm{B}$ in differing orders to prevent learning. In scenario A, candidates attempted intubation using the Mackintosh laryngoscope. In scenario B, candidates attempted insertion, ventilation and intubation using the ILMA (table 1).

A bougie was not made available to the paramedics as it is not part of their standard equipment.

\section{RESULTS}

One hundred percent of the paramedics were able to intubate a simulated difficult airway using the ILMA versus $0 \%$ of those using the Mackintosh laryngoscope.

\section{DISCUSSION}

In this study, the ILMA was superior to the Mackintosh laryngoscope for intubation. The authors were not trying to validate ILMA use in the unanticipated difficult intubation, but the ability of paramedics to master this airway device. This study has shown that paramedics are able to ventilate and intubate successfully with the ILMA even when unable to intubate with a laryngoscope. In an out-of-hospital environment where intubation is more difficult, we believe that if an ILMA is inserted successfully to maintain an airway and the patient's airway reflexes are obtunded, the paramedics can then more successfully proceed to secure that airway to reduce the risk of aspiration.

The ILMA does have a learning curve. The results from this study reflect this, with some candidates taking longer to achieve ventilation and successful intubation.

Despite the authors' best efforts, however, there do remain some elements of bias. All candidates were aware that the scenarios involved a difficult intubation, which may have affected their efforts with the laryngoscope.

This study has successfully established the ability of paramedics to use the ILMA if a difficult intubation is encountered in a hospital setting. Further out-of-hospital assessment of the ILMA's performance is required.

Until recently, only reusable ILMAs have been available. Disposable ILMAs are currently under trial and therefore this current financial and practical obstacle (ie, cleaning and tracing) for use by paramedics should be resolved.

\section{ACKNOWLEDGEMENTS}

We thank Mr John Careless (the Three Shires Ambulance Service) and Drs Jill Mollison and Ros Weatherall (Oxford Centre for Statistics in Medicine) for their help in the completion of this study.

\section{Authors' affiliations \\ Robert William Menzies, Northampton General Hospital, Cliftonville, Northampton, UK \\ Hamid Manji, Milton Keynes General Hospital, Standing Way, Eaglestone, UK \\ Competing interests: None declared.}

One of the intubating laryngeal masks used for this study was donated by Intavent.

Abbreviations: ILMA, intubating laryngeal mask airway 
Table 1 Candidates' ability to intubate with the Mackintosh laryngoscope (scenario A) and the intubating laryngeal mask airway (scenario B)

\begin{tabular}{|c|c|c|c|c|c|c|c|}
\hline Candidate & $\begin{array}{l}\text { Ability to intubate } \\
\text { with Mackintosh } \\
\text { laryngoscope }\end{array}$ & $\begin{array}{l}\text { Ability to ventilate } \\
\text { using the ILMA }\end{array}$ & $\begin{array}{l}\text { Time to successful } \\
\text { ventilation with the } \\
\text { ILMA (s) }\end{array}$ & $\begin{array}{l}\text { Ability to } \\
\text { intubate using } \\
\text { the ILMA }\end{array}$ & $\begin{array}{l}\text { Time to successful } \\
\text { intubation with the } \\
\text { ILMA (s) }\end{array}$ & $\begin{array}{l}\text { Number of } \\
\text { attempts at } \\
\text { intubation with } \\
\text { the ILMA }\end{array}$ & $\begin{array}{l}\text { Time from } \\
\text { ventilation to } \\
\text { intubation ILMA (s) }\end{array}$ \\
\hline 1 & No & Yes & 31 & Yes & 98 & 1 & 67 \\
\hline 2 & No & Yes & 41 & Yes & 68 & 1 & 27 \\
\hline 3 & No & Yes & 31 & Yes & 70 & 1 & 39 \\
\hline 4 & No & Yes & 31 & Yes & 88 & 1 & 57 \\
\hline 5 & No & Yes & 48 & Yes & 88 & 1 & 40 \\
\hline 6 & No & Yes & 31 & Yes & 62 & 1 & 31 \\
\hline 7 & No & Yes & 44 & Yes & 78 & 1 & 34 \\
\hline 8 & No & Yes & 33 & Yes & 71 & 1 & 38 \\
\hline 9 & No & Yes & 34 & Yes & 70 & 1 & 36 \\
\hline 10 & No & Yes & 32 & Yes & 63 & 1 & 31 \\
\hline 11 & No & Yes & 33 & Yes & 59 & 1 & 26 \\
\hline 12 & No & Yes & 31 & Yes & 61 & 1 & 30 \\
\hline 13 & No & Yes & 31 & Yes & 72 & 1 & 41 \\
\hline 14 & No & Yes & 44 & Yes & 149 & 2 & 105 \\
\hline 15 & No & Yes & $116^{*}$ & Yes & 160 & $\overline{1}$ & 44 \\
\hline 16 & No & Yes & 24 & Yes & 78 & 1 & 54 \\
\hline 17 & No & Yes & 49 & Yes & $254^{*}$ & 3 & 205 \\
\hline 18 & No & Yes & 61 & Yes & 87 & 1 & 26 \\
\hline 19 & No & Yes & 34 & Yes & 53 & 1 & 19 \\
\hline 20 & No & Yes & 53 & Yes & 75 & 1 & 22 \\
\hline 21 & No & Yes & 56 & Yes & 108 & 1 & 52 \\
\hline 22 & No & Yes & $92^{*}$ & Yes & 132 & 1 & 40 \\
\hline 23 & No & Yes & 45 & Yes & 80 & 1 & 35 \\
\hline
\end{tabular}

* ILMA, intubating laryngeal mask airway. Indicates where repositioning of the ILMA was required. Candidates 15, 17 and 22 required 2, 1 and 1 reposition(s) of the ILMA, respectively.

Ability to successfully intubate using the Mackintosh laryngoscope in scenario $A$ was $0 \%$ vs $100 \%$ for the ILMA ( $p<0.001$ ). Ventilation with the ILMA was possible in all cases.

\section{REFERENCES}

Combes X, Le Roux B, Suen P, et al. Unanticipated difficult airway in anaesthetized patients: prospective validation of a management algorithm. Anaesthesiology 2004; 100:1146-50.

2 Lim CL, Hawthorne L, Ip-Yam PC. The intubating laryngeal mask airway (ILMA) in failed and difficult intubation. Anaesthesia 1998;53:929-30.

3 Brain Al, Verghese C, Addy EV, et al. The intubating laryngeal mask II: a preliminary clinical report of a new means of intubating the trachea. Br J Anaesthesia 1997;79:704-9.

4 Henderson JJ, Popat MT, Latto IP, et al. Difficult Airway Society guidelines for management of the unanticipated difficult intubation. Anaesthesia 2004;59:675-94.
5 Kurola J, Pere P, Niemi-Murola L, et al. Comparison of airway management with the intubating laryngeal mask, laryngeal tube and Cobra PLA by paramedical students in anaesthetized patients. Acta Anaesthesiol Scand 2006;50:40-4

6 Levitan RM, Ochroch EA, Stuart S, et al. Use of the intubating laryngeal mask airway by medical and nonmedical personnel. Am J Emerg Med 2000;18:12-16.

7 Reeves MD, Skinner MW, Ginifer CJ. Evaluation of the intubating laryngeal mask used by occasional intubators in simulated trauma. Anaesth Intens Care 2004;32:73-6.

8 Cormack RS, Lehane J. Difficult intubation in obstetrics. Anaesthesia 1984;39:1105-11. 